\title{
COMMENTARY
}

\section{Well-Being: A Missing Component of Professionalism?}

\author{
Maria Miller Thurston, PharmD, ${ }^{\mathrm{a}, \mathrm{b}}$ Dana Hammer, MS, $\mathrm{PhD}^{\mathrm{c}}$ \\ ${ }^{\text {a }}$ Mercer University, College of Pharmacy, Atlanta, Georgia \\ ${ }^{\mathrm{b}}$ Editorial Board Member, American Journal of Pharmaceutical Education, Arlington, Virginia \\ ${ }^{\mathrm{c}}$ University of Colorado, Skaggs School of Pharmacy and Pharmaceutical Sciences, Aurora, Colorado
}

Corresponding Author: Maria Miller Thurston, Mercer University, College of Pharmacy, 3001 Mercer University Dr., Atlanta, GA 30341. Tel: 678-547-6253. Email: thurston_mm@mercer.edu

Submitted July 14, 2021; accepted August 5, 2021; ePublished August 2021

Enhancing student pharmacist professionalism through co-curricular efforts has been gained much attention in pharmacy education since release of Standards 2016. Interestingly, traditional and current definitions and attributes of professionalism do not include components of well-being; ideas of altruism and self-sacrifice predominate. However, it is imperative that student pharmacists are provided with the tools, resources, and time needed to invest in themselves to maintain their well-being, which in turn, allows them to fulfill our profession's standards of professional conduct and engagement. Thankfully, while seeming to conflict based on classic interpretations, practicing self-care to promote our personal well-being is not in conflict with being an altruistic, self-sacrificing professional. This commentary explores the interplay between the two constructs and postulates that some issues related to student pharmacists' unprofessional behavior can be linked to a lack of well-being. Therefore, pharmacy educators should consider incorporating well-being initiatives into efforts focused on refining student pharmacist professionalism.

Keywords: student pharmacist, well-being, self-care, professionalism, relationship

Student pharmacist professionalism and well-being are of particular relevance and importance in pharmacy education today, as the COVID-19 pandemic has dominated the health care space in recent months. Student pharmacists have played vital roles in patient care as frontline workers during the pandemic, through their internships within health systems, at community pharmacies, and as integral members of mass COVID-19 vaccination efforts. The heightened levels of responsibility and consequence during these times, that even seasoned professionals are feeling, can be especially taxing on the mental health and well-being of student pharmacists. When new and shifted professional obligations are layered on top of existing academic, financial, and family-related responsibilities, some students may find themselves overburdened and exhausted from the rigor of overwhelming demands and unrelenting self-sacrifice. While stress and pressure in the short-term can stimulate drive and motivation, allowing us to "rise to the challenge," prolonged stress may lead to chronic fatigue and burnout. Particularly during times of global crisis, people are known to come together to work tirelessly toward a cause, demonstrating high levels of altruism. However, this high level of motivation and enthusiasm may not be sustainable long-term and often wanes overtime. Then, when feelings of burnout may arise, they can compromise our ability to make sound decisions, leading to behaviors viewed as unethical or unprofessional. It is imperative that student pharmacists are provided with the tools, resources, and time needed to invest in themselves in order to maintain their well-being, which in turn, allows them to fulfill our profession's standards of professional conduct and engagement. It is quite possible that some issues related to student pharmacists' unprofessional behavior can be linked to a lack of well-being; well-being initiatives could be a missing component when it comes to efforts focused on enhancing student pharmacist professionalism. Afterall, how can you be altruistic if you do not care for yourself first? Therefore, should Colleges of Pharmacy adopt initiatives to promote student wellness in order to maximize professionalism? Additionally, one may ask, can these two constructs co-exist in harmony or are they in opposition of each other? Before exploring this relationship further, it may first be helpful to understand the history of professionalism and its associated components.

Scholars have worked to define professionalism for many years, and several definitions and defining traits exist in the literature, many with altruism at their core. ${ }^{1}$ Parsons and colleagues described a characteristic of "collectivity orientation" which implies a sense of the common needs in precedence over selfish needs. ${ }^{2}$ As a result of the autonomy and special recognition bestowed upon professions, there is higher trust, expectations, and standards for professionals. These ideas led to the working definition of professionalism for the American Pharmaceutical Association-Academy of Students of Pharmacy/American Association of Colleges of Pharmacy-Council of Deans (APhA-ASP/AACP-COD) Task 
Force on Professionalization: "displaying values, beliefs and attitudes that put the needs of another person above your personal needs." ${ }^{3}$ This task force went on to publish one of the sentinel works about student professionalism in pharmacy, with this definition as its foundation. ${ }^{4}$ The Oath of Pharmacist, Pledge of Professionalism, and Pharmacists' Code of Ethics also describe behaviors that are expected of all pharmacists; the basis of these codes are trustworthy service to others. Interestingly, traditional and current definitions and attributes of professionalism do not include well-being.

Overall, professionalism is a widely known and accepted construct within pharmacy education and the profession itself. It can be assessed through various methods and validated instruments, which has led to a plethora of literature. Additionally, with the recent incorporation of key elements of Standard 4 within Doctor of Pharmacy programs, many institutions have implemented initiatives and co-curricula aimed at further enhancing student pharmacist professionalism. Several of these programs include professional seminars, student organizational involvement with leadership opportunities, service learning events, and other professional development activities. ${ }^{5}$ However, there may still remain an opportunity to hone certain professional attributes within the affective domain, which could consist of efforts focused on enhancing well-being. ${ }^{6}$

Well-being is another element pertaining to the affective domain, but not often cited in descriptions. ${ }^{6}$ While there is no single definition of well-being, the Centers for Disease Control and Prevention states that "well-being includes the presence of positive emotions and moods, the absence of negative emotions, satisfaction with life, fulfillment and positive functioning." In turn, well-being may be viewed as innate, but it can be influenced by several factors and encompasses an emphasis on personal wellness and self-care. In contrast to professionalism, well-being is only beginning to come into focus within higher education and pharmacy practice; however, it is of utmost importance. While there is substantial literature regarding mental health, stress reduction, quality of life, well-being, and the impact of their associated interventions within other professional student bodies, less data exists related to student pharmacist well-being. Additionally, there is only brief mention of student pharmacist well-being within the current accreditation Standards, with Standards 14 and 15 touching on the topic related to offering financial, mental, and physical wellness services. ${ }^{8}$ However, recent literature suggests a great opportunity to enhance student pharmacist well-being as data indicate poor student scores related to stress, mental health-related quality of life, and coping ability. ${ }^{9}$ Furthermore, it has been noted that well-being declines as a student progresses in the curriculum, with higher rates of student stress, anxiety, and depression being reported later in the pharmacy curriculum. ${ }^{10,11}$

Yet until now, one of the phenomena that is not necessarily discussed in scholarly literature is the relationship between aspects of personal well-being, such as stress, and professionalism. There are limited data available on the aforementioned relationship. ${ }^{12} \mathrm{We}$ know that society has expectations of professional-based characteristics noted above; however, when those expectations are not met, it usually makes headlines, even if the professional was "off-duty." Consider stories of a physician that abuses a partner, a theologian that is cited for tax evasion, or an educator with a substance abuse problem. Although those kinds of scenarios may happen with other members of society, they do not usually become publicized unless they happen to members of society who are not expected to have those sorts of problems. As a member of a profession, society expects us to behave in certain ways all the time, not just when performing our jobs. This can be challenging as an early career professional, living up to and fulfilling others' needs and expectations all the time. Intense workloads are often required of pharmacists in training. These pharmacy learners demonstrate their commitment through altruistic behaviors such as working extended hours at the expense of personal time.

Thankfully, while seeming to conflict based on classic interpretations, practicing self-care to promote our personal well-being is not in conflict with being an altruistic, self-sacrificing professional. You have to take care of yourself before taking care of others or eventually you will have nothing left to give of yourself. Traditionally, student pharmacists have been trained to adopt a "patient first" mentality, sometimes at the expense of their own needs. More recently, however, it has been suggested that the triple aim to optimize health system performance be revised to a quadruple aim which includes a new emphasis on health care provider well-being and improving the work-life of the care team in order to minimize provider burnout and enhance patient safety.$^{13}$ Burnout, as a result of chronic stress, is one of the biggest threats to professionalism and can erode professionalism at its foundation. You see the influence of stress on professionalism when a student pharmacist makes a poor decision when under an extreme amount of pressure, like cheating on a high-stakes exam. However, if that same student were previously taught stress management techniques to build resilience, the core tenets of professionalism as outlined by Smith, ${ }^{1}$ such as self-imposed and enforced values and behavior, may have been preserved.

So how do we know when we need to take care of ourselves first and put others' needs second? As noted, constant and immense amounts of stress at work can lead to a phenomenon known as burnout, which can have deleterious consequences on our physical and mental well-being. This same concept of burnout may also be applied to a student's "work" in pharmacy school. The presence of burnout within pharmacy practice faculty has been clearly documented 
within the literature, ${ }^{14}$ leading us to postulate on the effect this may have on student pharmacists. Therefore, it is our job as pharmacy educators to be aware of this finding and act to address the issue within ourselves and our institutions, while also dedicating ourselves to enhancing student pharmacist well-being using existing literature as a guide. In a study by Babal and colleagues, first-year student pharmacists perceived five key areas that influenced their well-being: workload, learning environment culture and values, meaningful pharmacy school experiences, relationships, and personal factors. ${ }^{15}$ Additionally, various mindfulness-based programs have been studied in health care professional student populations with favorable results. ${ }^{16,17}$ Another pharmacy program embedded optional well-being challenges within a required didactic course to encourage student engagement in protective self-care behaviors. ${ }^{18}$ Finally, a formalized Mental Health First Aid (MHFA) training course involving student pharmacists has shown to help to decrease stigmatizing beliefs among pharmacy students, ${ }^{19}$ which may help to foster an environment of open dialog and inclusivity related to well-being issues. To promote self-awareness, suggest that students utilize the My Well-being Index assessment (https://app.mywellbeingindex.org/account_setup) to identify early warning signs of burnout and take immediate actions to mitigate the effects.

Unfortunately, it is often not until a catastrophic event occurs in life that we realize the importance of prioritizing our own health and practicing self-compassion. As faculty, we can normalize conversations involving conflicts between personal and professional demands and guide students in decision making processes as well as the necessary negotiations and compromises of life. Transparency and grace are of the utmost importance during these interactions, demonstrating to students that they are not alone in such struggles. Encouraging the practice of mindfulness, being present in the moment, as well as uplifting self-talk may help students to center and ground themselves. Colleges may enact programs to support the development and maintenance of both professionalism and well-being. One way is through helping students develop meaning in their "work" through intentional mentoring/advising programs, as well as formal training programs involving mindfulness and MHFA. Educators can also provide students with dedicated time for stillness and self-reflection. It is difficult to be present in the moment to allow for rejuvenation and thoughtfulness when we are incessantly connected to technology, for example. Strategies are needed for students to bring non-judgmental awareness to and contemplate challenges, so they may formulate an appropriate response for their unique professional journey. Many professional pharmacy organizations (APhA, ASHP, NCPA, and AACP) also provide resources on their websites that Colleges may utilize to develop intentional and tailored programs. Finally, the AACP 2019 House of Delegates approved a policy introduced by the 2018-2019 Academic Affairs committee that states: "AACP affirms that fostering leader, faculty, staff, and student well-being is a vital responsibility of the academy and individual schools and colleges." 20 The recently created AACP Well-being Connect Community and the 2021-2022 Student Affairs Committee are also increasing awareness of and promoting inclusion of well-being programs into pharmacy schools.

Although seemingly in competition, prioritizing personal well-being through incorporation of self-care strategies can indeed save lives, by allowing one to be fully present in the moment and dedicated to others through genuine professional and altruistic actions. In this way, well-being should certainly become one of the many components of professionalism. Student pharmacists, with institutional and faculty support, must engage in self-care to be the utmost professional in the truest sense of the word. Various resources are available and under development to foster well-being initiatives.

\section{REFERENCES}

1. Smith MC. Implications of 'professionalization' for pharmacy education. Am J Pharm Educ. 1970;34:16-32.

2. Parsons T. The Social System. Glencoe, IL: The Free Press: 1951.

3. Beardsley RS. Chair report of the APhA-ASP/AACP-COD Task Force on Professionalization: Enhancing professionalism in pharmacy education and practice. Am J Pharm Educ. 1996;60:26S-28S.

4. APhA-ASP/AACP-COD Task Force on Professionalism. White Paper on Pharmacy Student Professionalism. $J$ Am Pharm Assoc. 2000;40:96-102.

5. Maerten-Rivera JL, Chen A, Augustine J, et al. Co-curriculum implementation and assessment in accredited doctor of pharmacy programs. Am J Pharm Educ. 2020;84(3):7569. doi:10.5688/ajpe7569.

6. Accreditation Council for Pharmacy Education. Guidance for the Accreditation Standards and Key Elements for the Professional Program in Pharmacy Leading to the Doctor of Pharmacy Degree ("Guidance for Standards 2016"). Published February 2015. https://www.acpe-accredit.org/pdf/GuidanceforStandards2016FINAL.pdf. Accessed July 2, 2021.

7. CDC. Well-Being Concepts. Centers for Disease Control and Prevention. Published 2019. https://www.cdc.gov/hrqol/wellbeing.htm. Accessed July 2, 2021. 
8. Accreditation Council for Pharmacy Education. Accreditation Standards and Key Elements for the Professional Program in Pharmacy Leading to the Doctor of Pharmacy Degree ("Standards 2016"). Published February 2015. https://www.acpe-accredit.org/pdf/Standards2016FINAL.pdf. Accessed July 2, 2021.

9. Hirsch JD, Nemlekar P, Phuong P, et al. Patterns of Stress, Coping and Health-Related Quality of Life in Doctor of Pharmacy Students. Am J Pharm Educ. 2020;84(3):7547. doi:10.5688/ajpe7547

10. Hagemeier NE, Carlson TS, Roberts CL, Thomas M. A Longitudinal Analysis of First Professional Year Pharmacy Student Well-being. Am J Pharm Educ. 2020 Jul;84(7):ajpe7735. doi: 10.5688/ajpe7735. PMID: 32773830; PMCID: PMC7405294.

11. Silva RG, Figueiredo-Braga M. Evaluation of the relationships among happiness, stress, anxiety, and depression in pharmacy students. Curr Pharm Teach Learn. 2018;10(7):903-910. doi:10.1016/j.cptl.2018.04.002

12. Tak C, Henchey C, Feehan M, Munger MA. Modeling Doctor of Pharmacy Students' Stress, Satisfaction, and Professionalism Over Time. Am J Pharm Educ. 2019;83(9):7432. doi:10.5688/ajpe 7432

13. Bodenheimer T, Sinsky C. From Triple to Quadruple Aim: Care of the Patient Requires Care of the Provider. The Annals of Family Medicine. 2014;12 (6):573-576. doi:10.1370/afm.1713

14. El-Ibiary SY, Yam L, Lee KC. Assessment of Burnout and Associated Risk Factors Among Pharmacy Practice Faculty in the United States. Am J Pharm Educ. 2017;81(4):75. doi:10.5688/ajpe81475

15. Babal JC, Abraham O, Webber S, Watterson T, Moua P, Chen J. Student Pharmacist Perspectives on Factors That Influence Wellbeing During Pharmacy School. Am J Pharm Educ. 2020;84(9):ajpe7831. doi:10.5688/ajpe7831

16. Kinser P, Braun S, Deeb G, Carrico C, Dow A. "Awareness is the first step": An interprofessional course on mindfulness \& mindful-movement for healthcare professionals and students. Complement Ther Clin Pract. 2016;25:18-25. doi:10.1016/j.ctcp.2016.08.003

17. Lemay V, Hoolahan J, Buchanan A. Impact of a Yoga and Meditation Intervention on Students' Stress and Anxiety Levels. Am J Pharm Educ. 2019;83(5):7001. doi:10.5688/ajpe7001

18. Cain J. Effectiveness of Issuing Well-being Challenges to Nudge Pharmacy Students to Adopt Well-being Protective Behaviors. Am J Pharm Educ. 2020;84(8):ajpe7875. doi:10.5688/ajpe7875

19. McCormack Z, Gilbert JL, Ott C, Plake KS. Mental health first aid training among pharmacy and other university students and its impact on stigma toward mental illness. Curr Pharm Teach Learn. 2018;10(10):1342-1347. doi:10.1016/j.cptl.2018.07.001

20. American Association of Colleges of Pharmacy House of Delegates Cumulative Policies 1980-2020. https://www.aacp.org/sites/default/files/2021-04/hod_commulative_policy_1980_2020.pdf. Accessed July 2, 2021. 